\title{
Myocardial protection from ischemia/reperfusion injury by exogenous galanin fragment
}

\author{
Andrei Timotin ${ }^{1,2}$, Oleg Pisarenko ${ }^{3}$, Maria Sidorova ${ }^{3}$, Irina Studneva ${ }^{3}$, Valentin \\ Shulzhenko ${ }^{3}$, Marina Palkeeva ${ }^{3}$, Larisa Serebryakova ${ }^{3}$, Aleksander Molokoedov ${ }^{3}$, \\ Oksana Veselova ${ }^{3}$, Mathieu Cinato ${ }^{1,2}$, Helene Tronchere ${ }^{1,2}$, Frederic Boal ${ }^{1,2, *}$, \\ Oksana Kunduzova ${ }^{1,2, *}$ \\ ${ }^{1}$ National Institute of Health and Medical Research (INSERM), Toulouse, France \\ ${ }^{2}$ University of Toulouse, UPS, Institute of Metabolic and Cardiovascular Diseases, Toulouse, France \\ ${ }^{3}$ Russian Cardiology Research-and-Production Complex, Moscow, Russian Federation, Russia \\ *These authors have contributed equally to this work \\ Correspondence to: Oksana Kunduzova, email: Oxana.Koundouzova@inserm.fr \\ Keywords: galanin (2-11), heart, ischemia and reperfusion, energy metabolism, ROS production \\ Received: November 02, $2016 \quad$ Accepted: January 09, $2017 \quad$ Published: February 03, 2017
}

\section{ABSTRACT}

Background and purpose: Galanin is a multifunctional neuropeptide with pleiotropic roles. The present study was designed to evaluate the potential effects of galanin (2-11) (G1) on functional and metabolic abnormalities in response to myocardial ischemia-reperfusion (I/R) injury.

Experimental approach: Peptide G1 was synthesized by the 9-fluorenylmethoxycarbonyl (Fmoc)-based solid-phase method. The chemical structure was identified by ${ }^{1} \mathrm{H}-\mathrm{NMR}$ spectroscopy and mass spectrometry. Experiments were conducted using a rat model of $I / R$ injury in vivo, isolated perfused rat hearts ex vivo and cultured rat cardiomyoblast $\mathrm{H} 9 \mathrm{C} 2$ cells in vitro. Cardiac function, infarct size, myocardial energy metabolism, hemodynamic parameters, plasma levels of creatine kinase-MB (CK-MB) and lactate dehydrogenase (LDH) were measured in order to evaluate the effects of $G 1$ on myocardial I/R injury.

Key results: Treatment with $\mathrm{G1}$ increased cell viability in a dose-dependent manner, inhibited cell apoptosis and excessive mitochondrial reactive oxygen species (ROS) production in response to oxidative stress in $\mathrm{H} 9 \mathrm{C} 2$ cells. Pre- or postischemic infusion of $\mathbf{G 1}$ enhanced functional and metabolic recovery during reperfusion of the ischemic isolated rat heart. Administration of $\mathrm{G1}$ at the onset of reperfusion significantly reduced infarct size and plasma levels of CK-MB and LDH in rats subjected to myocardial I/R injury.

Conclusions and implications: These data provide the first evidence for cardioprotective activity of galanin $\mathbf{G 1}$ against myocardial I/R injury. Therefore, peptide $\mathbf{G 1}$ may represent a promising treatment strategy for ischemic heart disease.

\section{INTRODUCTION}

Galanin is a highly conserved 29-(30 in human) amino acid neuropeptide with multiple biological functions. Galanin modulates the release and secretion of many neurotransmitters and hormones in the central nervous system and periphery, such as acetylcholine, gastrin, insulin, dopamine, somatotropin and prolactin. Central administration of galanin stimulates feeding behavior and energy balance that impact body weight regulation [1]. Galanin is involved in central cardiovascular regulation, which affects the blood pressure and the heart rate [2]. Administration of galanin into the rostral ventrolateral medulla produces a weak hypotension and tachycardia effect by reducing the sympathetic vasomotor tone in rats [3], which may be blocked by the intracerebroventricular 
injection of galanin antagonist M40 [4]. Recent studies suggest that galanin and its fragment play a major role in the regulation of metabolic homeostasis in cardiac muscle and galanin is an important hormone relative to diabetic heart [4]. The endogenous galanin, acting through its central receptor, has an important attribute to glucose transporter 4 (GLUT4) regulation, leading to enhanced insulin sensitivity and glucose uptake in cardiac muscle of type 2 diabetic rats [5]. In response to ischemia-reperfusion, galanin may stimulate sensory nerve regeneration and promote the regrowth of cardiac sensory nerves $[6,7]$. Furthermore, galanin protects the heart muscle against hypoxia-induced contractile disturbances to improve inotropic action [8]. Although galanin and its fragments are involved in central cardiovascular regulation, the therapeutic potential of galanin-receptor ligands for coronary heart disease remains unexplored.

Galanin is involved in the regulation of physiological processes in peripheral organ systems via neuronal mechanisms and direct receptor mediated cellular effects. Currently three types of galanin receptors (GalR1, GalR2, and GalR3) have been identified by molecular cloning and characterized pharmacologically in various species [9]. They are members of the G-protein coupled receptor superfamily, but have differences in their functional coupling and signaling activities. All subtypes of galanin receptors are distributed in the hypothalamus, paraventricular nucleus, hippocampus, amygdale, peripheral nervous system and other tissues, including the heart [10]. The N-terminal end of galanin is highly conserved between different species, and the first 15 amino acid residues were found to be responsible for agonistic receptor binding [11]. The C-terminal region (amino acid residue 17-29) varies in most species and has a weak receptor affinity [11]. All three galanin receptor subtypes couple to $\mathrm{G}_{\mathrm{i} / \mathrm{o}}$ and inhibit adenylyl cyclase causing a decrease of the activity of the cAMP response element binding protein (pCREB). The activated pCREB may inhibit the Rab GTPase-activating protein (AS160), a substrate of Akt and GLUT4 translocation, thus promoting insulin resistance [11, 12]. GalR2 receptor signals through several classes of G-proteins and stimulates multiple intracellular pathways. Signaling via $G / 11$ activates phospholipase C (PLC) and protein kinase C (PKC) [13]. Activation of PLC leads to an increase in the hydrolysis of phosphatidylinositol $(4,5)$ bis-phosphate $\left(\mathrm{PI}(4,5) \mathrm{P}_{2}\right)$ and promotes $\mathrm{Ca}^{2+}$ release from the endoplasmic reticulum [14], suggesting that galanin signaling via GalR2 receptor may modulate multiple cell death mechanisms in the failing heart. In spite of a variety of potential galanin receptor ligands developed to elucidate the specific roles of galaninergic system, very few agonists have high selectivity towards GalR2 receptor. One of them is a short N-terminal galanin fragment $(2-11, \mathrm{G} 1)$ with no appreciable activation of GalR1 receptor [15]. The ability of this peptide to act as a non-GalR1 receptor agonist has provided evidence for the strong anti-kindling activities of G1. In fact, the action of G1 could be identified as antiepileptogenic, as judged by the complete prevention of both full motor seizures and of a post-kindling increase of hippocampal excitability [16]. However, the peripheral action of this peptide remains poorly understood. No data regarding the role of $\mathrm{G} 1$ in cardiac cells and cardiovascular diseases is available so far.

In the present study we have evaluated the effects of G1 on myocardial I/R injury in various experimental models including cardiomyoblasts, perfused isolated heart and the heart in situ.

\section{RESULTS}

\section{The effects of G1 on $\mathrm{H} 9 \mathrm{C} 2$ cell survival in response to stress}

To determine whether G1 affects cell survival in response to oxidative stress, we examined the dosedependent effects of the peptide on $\mathrm{H}_{2} \mathrm{O}_{2}$-induced loss of cardiomyoblast viability measured by ATP concentration. As shown in Figure 1, cell exposure to $400 \mu \mathrm{M} \mathrm{H}_{2} \mathrm{O}_{2}$ for 4 hours led to a significant reduction of the cell viability compared to control. Dose-response studies revealed that at the dose of 50 and $250 \mathrm{nM} \mathrm{G1}$ was able to prevent $\mathrm{H}_{2} \mathrm{O}_{2}$-induced decrease of cell survival. Next, we examined by terminal deoxynucleotidyltransferase dUTP nick end labeling (TUNEL) assay whether G1 affects apoptotic cell death in response to hypoxic stress. Because $50 \mathrm{nM}$ of G1 produced approximately a $20 \%$ increase in cardiomyoblast viability, we used this concentration in subsequent experiments. As shown in Figure 2, the exposure of $\mathrm{H} 9 \mathrm{C} 2$ cells to hypoxia caused a significant increase in the number of TUNELpositive cells as compared to normoxia. However, the treatment of cells with $50 \mathrm{nM}$ G1 significantly reduced hypoxia-induced apoptosis (Figure 2A-2B).

\section{The effects of G1 on hypoxia-induced mitochondrial ROS production in $\mathrm{H} 9 \mathrm{C} 2$ cells}

The excessive generation of ROS and impaired cellular metabolism are closely linked to cell death and myocardial damage [17]. To determine whether G1 could affect ROS generation in response to hypoxia, we examined the effects of G1 on mitochondrial superoxide $\left(\mathrm{O}_{2}^{-}\right)$production using the MitoSOX Red fluorescent probe. As shown in Figure 3A-3B, cell exposure to hypoxic stress caused a significant increase in $\mathrm{O}_{2}^{-}$production as compared to normoxia. Importantly, treatment of $\mathrm{H} 9 \mathrm{C} 2$ cells with $50 \mathrm{nM} \mathrm{G1}$ markedly prevented hypoxia-induced $\mathrm{O}_{2}{ }^{-}$formation (Figure 3A-3B).

\section{The cardioprotective potential of exogenous G1 in isolated rat hearts after $I / R$ injury}

To study the functional role of galanin fragment in the failing heart, we evaluated the effects of G1 on 


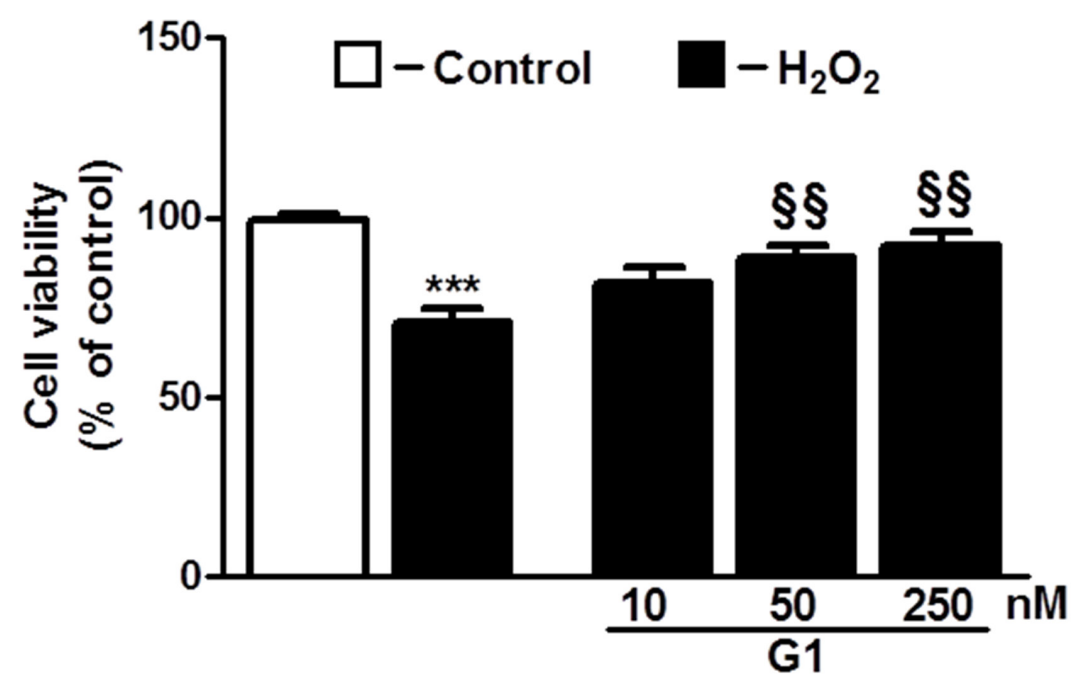

Figure 1: Dose-dependent effect of G1 on cell survival in response to oxidative stress. Treatment of cardiomyoblasts with G1 prevents $\mathrm{H}_{2} \mathrm{O}_{2}$-induced decrease of cell viability in a dose-dependent manner. The H9C2 were pretreated with G1 (10, 50, $\left.250 \mathrm{nM}\right)$ for $20 \mathrm{~min}$ and then exposed to $400 \mu \mathrm{M} \mathrm{H}_{2} \mathrm{O}_{2}$ for $4 \mathrm{~h}$. Values are the means $\pm \mathrm{SEM}$ for three experiments. $* * * P<0.001$, vs control; ${ }^{\xi} P<0.01$, vs $\mathrm{H}_{2} \mathrm{O}_{2}$ treatment.

A)
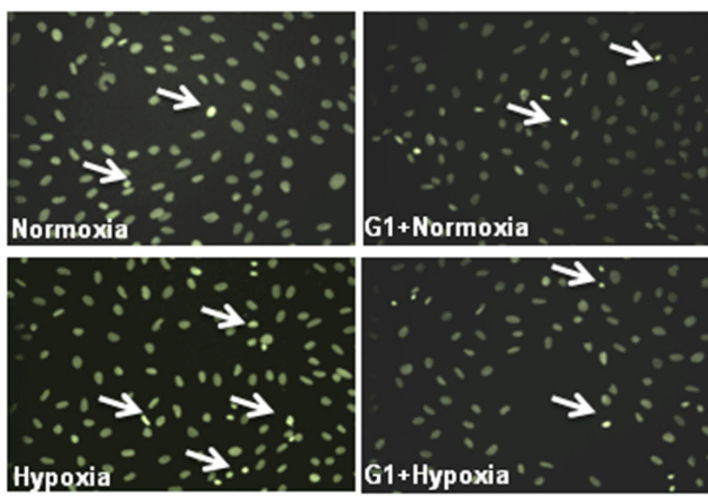

B)

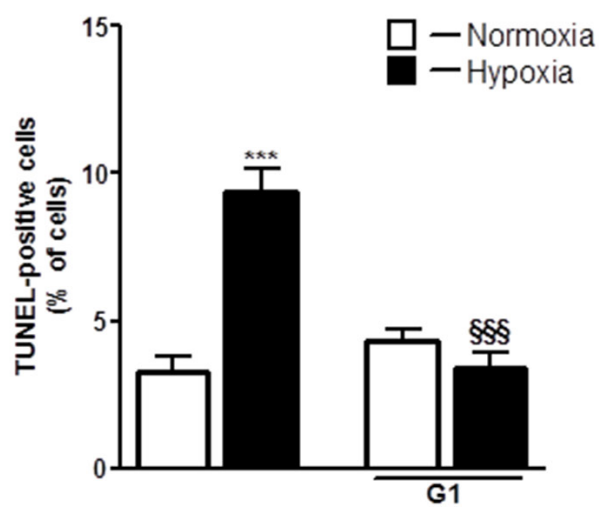

Figure 2: Effect of G1 on hypoxia-induced cell apoptosis. A. Representative fluorescence images of $\mathrm{H} 9 \mathrm{C} 2$ cells pretreated with $50 \mathrm{nM} \mathrm{G1}$ for $20 \mathrm{~min}$ and then exposed to normoxia or hypoxia $\left(1 \% \mathrm{O}_{2}\right)$ followed by reoxygenation. Apoptosis was measured by TUNEL assay in $\mathrm{H} 9 \mathrm{C} 2$ cells after $16 \mathrm{~h}$ of hypoxia followed by $4 \mathrm{~h}$ of reoxygenation. B. Quantitative analysis of TUNEL-positive cells in H9C2 cells. Values are the means \pm SEM from three experiments. ${ }^{* * *} P<0.001$, vs normoxia; ${ }^{\$ s} P<0.001$, vs hypoxia.

\section{A)}
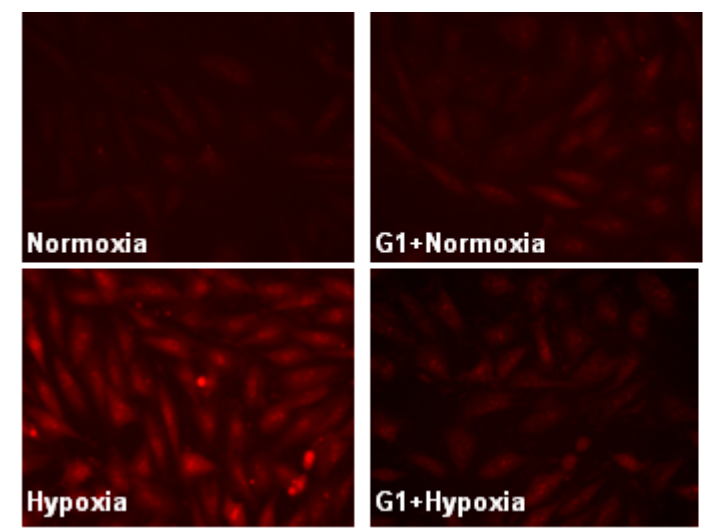

B)

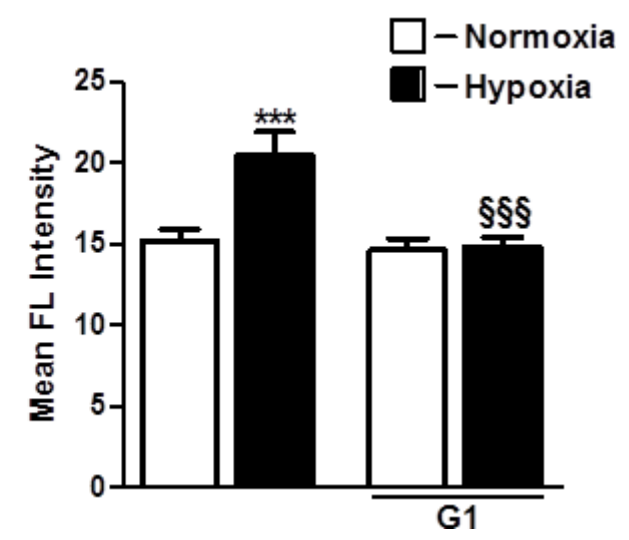

Figure 3: Effect of $\mathbf{G 1}$ on hypoxia-induced mitochondrial $\mathbf{O}_{2}$ - production. A. Representative fluorescence images of $\mathrm{H} 9 \mathrm{C} 2$ cells pretreated with $\mathrm{G} 1$ peptide. Mitochondrial $\mathrm{O}_{2}^{-}$formation was assessed by MitoSOX Red in $\mathrm{H} 9 \mathrm{C} 2$ cells exposed to 16h hypoxia followed by $4 \mathrm{~h}$ of reoxygenation. B. Quantitative analysis of mitochondrial $\mathrm{O}_{2}^{-}$production in $\mathrm{H} 9 \mathrm{C} 2$ cells exposed to normoxia or hypoxiareoxygenation. Values are the means \pm SEM from three experiments. $* * * P<0.001$ vs normoxia; $\$ \xi \$<0.001$ vs hypoxia. 
the recovery of perfused hearts subjected to I/R injury (Figure 4A). Infusion of peptide G1 before global ischemia or at onset of reperfusion enhanced recovery of cardiac function during reperfusion compared with control. A dose-dependent effect of G1 on recovery of cardiac output $(\mathrm{CO})$ by the end of reperfusion is shown on Figure 4B. The significant increase in $\mathrm{CO}$ recovery was observed after pre- or postischemic infusion of 80 $\mu \mathrm{M}$ G1 as compared with the control. The differences in $\mathrm{CO}$ recovery between the experimental and control groups became more pronounced with an increase in G1 concentration in Krebs-Henseleit bicarbonate buffer (KHB). The maximal response to G1 was observed at the concentration of $240 \mu \mathrm{M}$; at a higher concentration a dose-effect curve reached a plateau. Within the range of $80-280 \mu \mathrm{M}, \mathrm{CO}$ recovery was more effective when peptide infusion was performed after ischemia. A similar dose-dependent effects were obtained for recovery of the left ventricular $(\mathrm{LV})$ developed pressure $($ LVDP) $\times$ heart rate (HR) product (Figure 4C).

Cardiac function indices were compared at the end of reperfusion for preischemic (G1-I) and postischemic (G1-R) infusion of the optimal G1 concentration (240 $\mu \mathrm{M})$ in Table 1 . In addition to recovery of $\mathrm{CO}$, recovery of aortic output and stroke volume was also significantly higher in the G1-R group compared to the G1-I group. An augmented restoration of the LVDPxHR product in both G1 groups was due to better recovery of HR and LVDP comparing with control. A significant increase in LVDP was caused by a marked reduction of LV diastolic pressure during reperfusion. Both G1 groups exhibited an increase in coronary flow with concomitant reduction in coronary resistance in comparison with control. Data in Table 1 show that recovery of cardiac function was more effective after G1 administration at the onset of reperfusion.

Myocardial energy status is a critical aspect of cardiac function. We next evaluated the effects of exogenous G1 on the energy metabolism in isolated hearts in response to $\mathrm{I} / \mathrm{R}$. The control group exhibited poor recovery of energy metabolism at the end of reperfusion. A dramatic decrease in myocardial ATP to $31 \%$ of the initial content was accompanied by a reduction of adenine nucleotide pool ( $\Sigma \mathrm{AN})$ and adenylate energy charge (AEC) by 45 and $33 \%$, respectively, as compared to steady state values (Figure 5A-5B). Myocardial phosphocreatine ( $\mathrm{PCr}$ ) recovery was about $52 \%$ of the initial value, total creatine pool $(\Sigma \mathrm{Cr})$ was significantly reduced by $15 \%$, while myocardial lactate content was almost 5 times higher than steady state value (Figure 5C-5D). Pre- or postischemic infusion of G1 significantly enhanced restoration of ATP, $\Sigma \mathrm{AN}$ and increased AEC in reperfused hearts compared with control. These effects were combined with a significant increase in $\mathrm{PCr}$ recovery, better preservation of $\Sigma \mathrm{Cr}$ and a substantial reduction in myocardial lactate content. Recovery of metabolic state in the G1-R group was more effective than in the G1-I group. G1 infusion after ischemia improved preservation of ATP, $\Sigma$ AN and $\mathrm{PCr}$, and reduced lactate accumulation in myocardial tissue at the end of reperfusion in comparison with effects

\section{A}

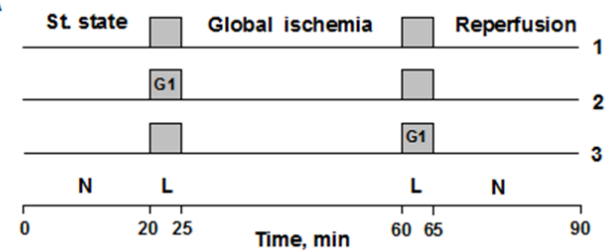
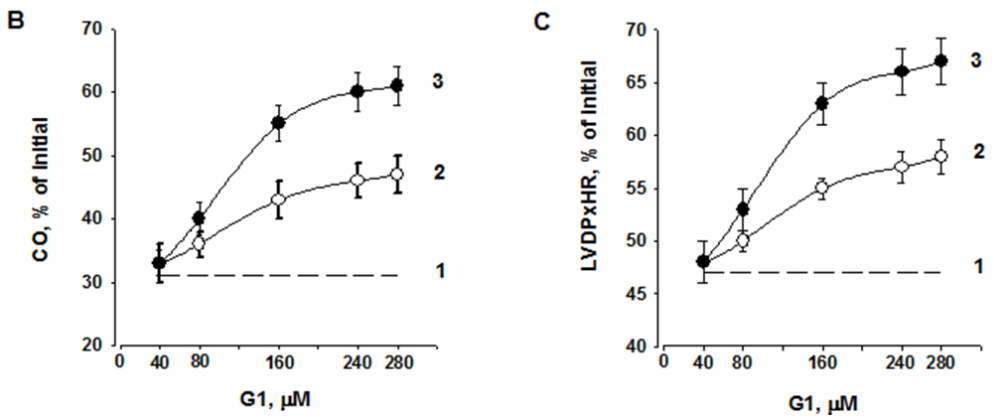

Figure 4: Dose-dependent effect of G1 infusion on functional recovery of isolated rat heart at the end of reperfusion. A. Study design including three groups: 1 - Control; 2 - G1 infusion before ischemia; 3 - G1 infusion after ischemia; L - a 5-min Langendorff perfusion at a flow rate of $4 \mathrm{ml} / \mathrm{min}$ before or after ischemia; $\mathrm{N}$, a working perfusion according to a method of Neely. B. Effects of peptide G1 on cardiac output (CO) recovery at the end of reperfusion. C. Effects of peptide G1 on the contractile function intensity index (left ventricular developed pressure $(\mathrm{LVDP}) \times$ heart rate $(\mathrm{HR}))$ recovery at the end of reperfusion. The values are expressed as means \pm SEM from 8 experiments. 
Table 1: Effect of infusion of $240 \mu \mathrm{M}$ G1 before (G1-I) and after global ischemia (G1-R) on recovery of isolated rat heats at the end of reperfusion

\begin{tabular}{|c|c|c|c|c|c|}
\hline & Steady state & Control & G1-R & GI-I & Vehicle \\
\hline Coronary flow, $\mathrm{ml} / \mathrm{min}$ & $17 \pm 2$ & $13 \pm 1^{\mathrm{a}}$ & $16 \pm 1^{b}$ & $14 \pm 1$ & $13 \pm 1^{\mathrm{a}}$ \\
\hline $\begin{array}{l}\text { Perfusion pressure, } \\
\text { mmHg }\end{array}$ & $62 \pm 4$ & $58 \pm 1$ & $60 \pm 1$ & $59 \pm 1$ & $58 \pm 1$ \\
\hline $\begin{array}{l}\text { Coronary resistance, } \\
\mathrm{mmHg} / \mathrm{ml}\end{array}$ & $3.62 \pm 0.03$ & $4.46 \pm 0.07^{\mathrm{a}}$ & $3.95 \pm 0.10 \mathrm{abc}$ & $4.20 \pm 0.13^{\mathrm{a}}$ & $4.45 \pm 0.13^{\mathrm{a}}$ \\
\hline $\begin{array}{l}\text { LV systolic pressure, } \\
\text { mmHg }\end{array}$ & $98 \pm 3$ & $69 \pm 1^{\mathrm{a}}$ & $85 \pm 2 \mathrm{abc}$ & $76 \pm 3^{\mathrm{ab}}$ & $69 \pm 2^{a}$ \\
\hline $\begin{array}{l}\text { LV diastolic pressure, } \\
\text { mmHg }\end{array}$ & $-3 \pm 1$ & $10 \pm 1^{\mathrm{a}}$ & $3 \pm 1 \mathrm{abc}$ & $6 \pm 1^{a b}$ & $10 \pm 1^{\mathrm{ac}}$ \\
\hline $\begin{array}{l}\text { LV developed pressure, } \\
\text { mm Hg }\end{array}$ & $101 \pm 1$ & $59 \pm 2^{\mathrm{a}}$ & $82 \pm 3$ ac & $70 \pm 4 \mathrm{ab}$ & $59 \pm 3^{\mathrm{a}}$ \\
\hline Heart rate, beat/min & $301 \pm 2$ & $238 \pm 3^{\mathrm{a}}$ & $272 \pm 5 \mathrm{abc}$ & $254 \pm 6^{\mathrm{ab}}$ & $238 \pm 5^{a}$ \\
\hline LVDP x HR, mmHg/min & $30380 \pm 373$ & $14186 \pm 525^{a}$ & $22318 \pm 1270^{a b c}$ & $17812 \pm 1309$ ab & $14052 \pm 969$ ac \\
\hline Aortic output, $\mathrm{ml} / \mathrm{min}$ & $26 \pm 3$ & $0 \pm 1^{\mathrm{a}}$ & $14+1 \mathrm{abc}$ & $7 \pm 1^{a b}$ & $0 \pm 1$ ac \\
\hline Cardiac output, ml & $43 \pm 2$ & $13 \pm 1^{\mathrm{a}}$ & $29 \pm 2^{\mathrm{abc}}$ & $21 \pm 2^{a b}$ & $13 \pm 1^{\mathrm{ac}}$ \\
\hline Stroke volume, $\mu \mathrm{l}$ & $144 \pm 1$ & $54 \pm 4^{\mathrm{a}}$ & $106 \pm 6^{\mathrm{abc}}$ & $81 \pm 8^{a b}$ & $53 \pm 5^{\mathrm{ac}}$ \\
\hline
\end{tabular}

The hearts were perfused as indicated in Materials and methods. Data are the mean \pm SEM for 10 experiments. ${ }^{a} p<0.05$ vs. steady state, ${ }^{\mathrm{b}} \mathrm{p}<0.05$ vs. control and vehicle; ${ }^{\mathrm{c}} \mathrm{p}<0.05$ vs. G1-I.

A

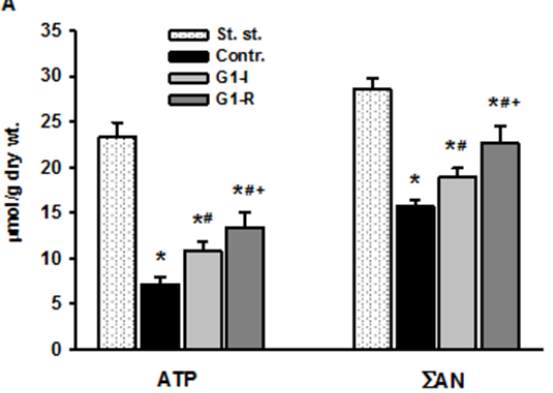

C

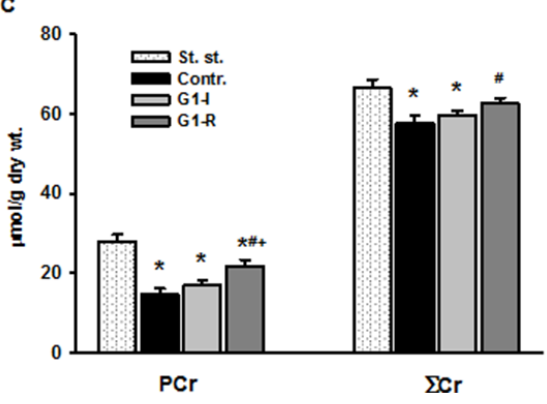

B

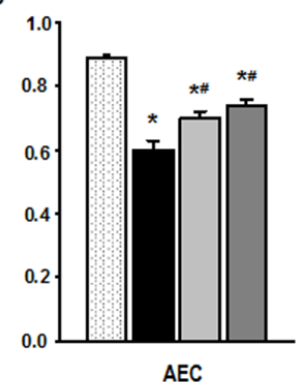

D

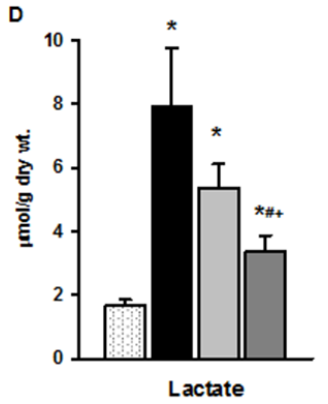

Figure 5: Effects of G1 infusion on metabolic state of isolated rat heart at the end of reperfusion. St. - steady state; Contr. - control; G1-I - peptide infusion at the dose of $240 \mu \mathrm{M}$ before ischemia; G1-R - peptide infusion at the dose of $240 \mu \mathrm{M}$ after ischemia. A. Pre- or postischemic infusion of G1 improved recovery of myocardial ATP and adenine nucleotide pool $(\Sigma A N)=(A T P+A D P+A M P)$ and B. adenylate energy charge $(\mathrm{AEC})=(\mathrm{ATP}+0.5 \mathrm{ADP}) / \Sigma \mathrm{AN})$ at the end of reperfusion. $\mathbf{C}$. Infusion of $\mathrm{G} 1$ increased recovery of myocardial phosphocreatine $(\mathrm{PCr})$, total creatine $(\Sigma \mathrm{Cr})=(\mathrm{PCr}+\mathrm{Cr})$ and $\mathbf{D}$. reduced myocardial lactate accumulation. Values are the means $\pm \mathrm{SEM}$ from 8 experiments. ${ }^{*} P<0.05$ vs. steady state; ${ }^{\#} P<0.05$ vs control, ${ }^{+} P<0.05$ vs G1-I. 
Table 2: Effects of G1 administration on systemic hemodynamic variables in anesthetized rats in vivo

\begin{tabular}{|c|c|c|c|}
\hline \multirow{2}{*}{ Group } & \multirow{2}{*}{ Steady state } & \multicolumn{2}{|c|}{ LAD reperfusion } \\
\hline & & $1-2 \mathrm{~min}$ & $60 \mathrm{~min}$ \\
\hline \multicolumn{4}{|c|}{$\mathrm{SAP}, \mathrm{mm} \mathrm{Hg}$} \\
\hline Control & $86 \pm 3$ & $85 \pm 2$ & $86 \pm 3$ \\
\hline G1-0.4 & $82 \pm 2$ & $63 \pm 2^{a b}$ & $81 \pm 4$ \\
\hline G1-0.7 & $84 \pm 2$ & $64 \pm 2^{a b}$ & $83 \pm 2$ \\
\hline G1-1.3 & $89 \pm 3$ & $69 \pm 3^{\text {a b }}$ & $87 \pm 2$ \\
\hline \multicolumn{4}{|c|}{ HR, beats /min } \\
\hline Control & $334 \pm 5$ & $331 \pm 4$ & $332 \pm 4$ \\
\hline G1-0.4 & $338 \pm 6$ & $314 \pm 7$ a b & $337 \pm 7$ \\
\hline G1-0.7 & $329 \pm 5$ & $306 \pm 6^{\mathrm{ab}}$ & $330 \pm 5$ \\
\hline G1-1.3 & $332 \pm 4$ & $246 \pm 4^{a b c d}$ & $327 \pm 6$ \\
\hline
\end{tabular}

G1 was administrated by i.v. bolus injection at the onset of reperfusion at doses of $0.4 ; 0.7$ or $1.3 \mu \mathrm{mol} / \mathrm{kg}$ (groups G1-0.4, G1-0.7 or G1-1.3, respectively). An equal volume of saline was injected in control. Values are expressed as mean $\pm \mathrm{SEM}$ for 12 experiments. Significant difference $(P<0.05)$ from: ${ }^{a}$ steady state; ${ }^{b}$ control; ${ }^{c} \mathrm{G} 1-0.4 ;{ }^{\mathrm{d}} \mathrm{G} 1-0.7$.

A

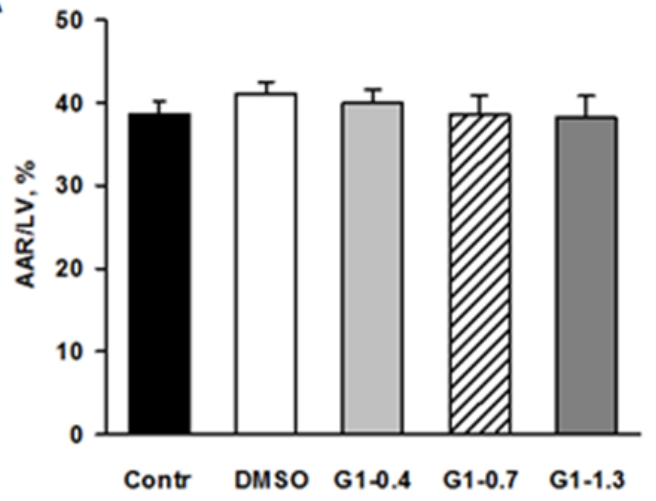

B

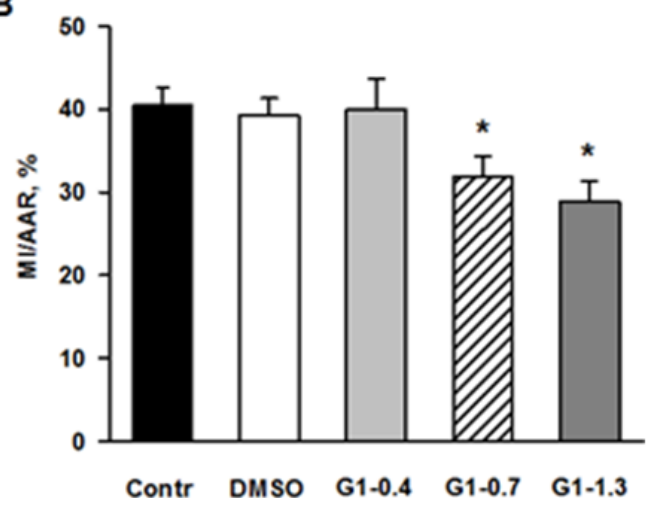

Figure 6: Effects of G1 on myocardial infarct size and area at risk in rats in vivo. Dose-dependent effects of peptide G1 on A. area at risk (AAR) and B. myocardial infarct size. AAR was expressed as percentage of the left ventricular weight (AAR/LV, \%) and myocardial infarct size (MI) was expressed as percentage of the AAR (MI/AAR, \%). Control - i.v. bolus injection of $0.5 \mathrm{ml}$ of saline; DMSO - i.v. bolus injection of $0.5 \%$ DMSO in saline; G1- i.v. bolus injection of peptide G1 at dose of $0.4,0.7 \mathrm{or} 1.3 \mu \mathrm{mol} / \mathrm{kg}$. Values are the means \pm SEM from 8 experiments. ${ }^{*} P<0.05$ vs control.
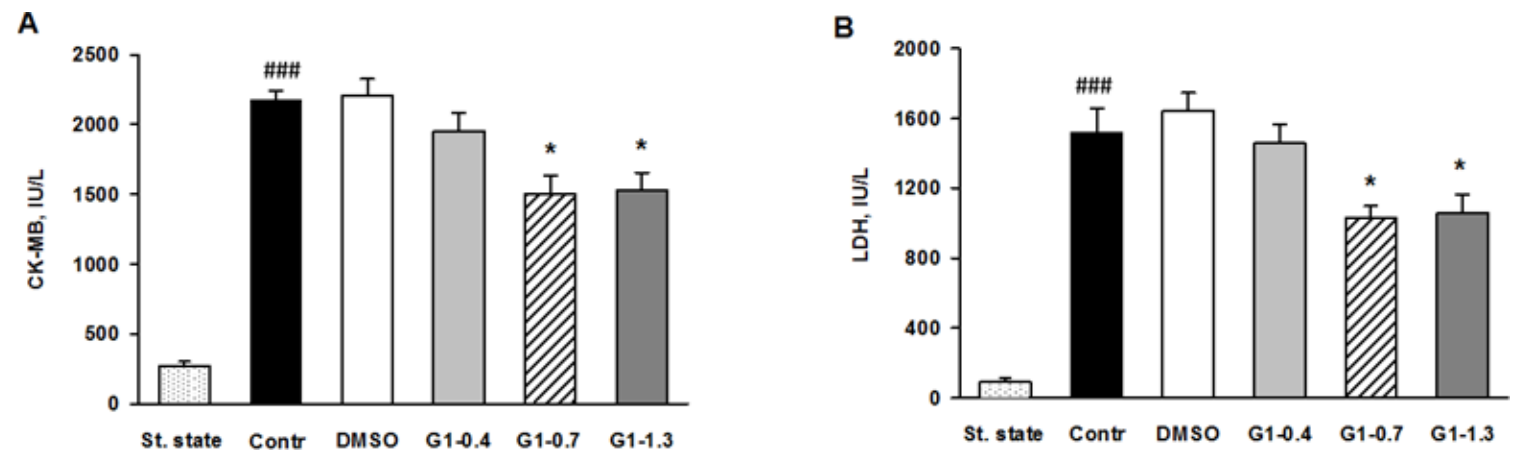

Figure 7: Effects of G1 on plasma level of necrosis markers in rats in vivo. Dose-dependent effects of peptide G1 on A. activity of creatine kinase-MB (CK-MB) and B. lactate dehydrogenase (LDH) in blood plasma. St. state - steady state; Control - i.v. bolus injection of $0.5 \mathrm{ml}$ of saline; DMSO - i.v. bolus injection of $0.5 \%$ DMSO in saline; G1- i.v. bolus injection of peptide G1 at dose of $0.4,0.7$ or 1.3 $\mu \mathrm{mol} / \mathrm{kg}$. Values are the means \pm SEM from 8 experiments. ${ }^{*} P<0.05$ vs Control; ${ }^{\#} P<0.001$ vs St. state. 
of preischemic peptide infusion. Thus, the experiments on perfused rat hearts clearly demonstrated metabolic and functional advantages of postischemic infusion with G1 over its administration prior to ischemia.

\section{The cardioprotective effects of exogenous G1 in anesthetized rats in vivo}

In the steady state, there were no differences in the systolic arterial pressure (SAP) or HR between the groups (Table 2). Bolus injection of saline after the period of left anterior descending (LAD) coronary artery occlusion did not affect SAP and HR during reperfusion in control. Treatment with G1 at a dose of $0.4,0.7$ or $1.3 \mu \mathrm{mol} / \mathrm{kg}$ resulted in a fall in SAP (on average by $23 \pm 4 \%$ of the initial value at the second min of reperfusion). By the end of reperfusion, SAP recovered to near baseline $(98 \pm 4 \%)$. A slight decrease in HR on average by $7 \pm 1 \%$ from baseline was observed in groups G1-0.4 and G1-0.7 at the first minute of reperfusion. It was accompanied by complete restoration of HR by the end of reperfusion. Similar hemodynamic changes were observed when G1 was administrated at a dose of 0.4 and $0.7 \mu \mathrm{mol} / \mathrm{kg}$ in shamoperated animals. In the G1-1.3 group, HR reduced to 73 $\pm 6 \%$ of the initial value at the first min of reperfusion and returned to baseline by the end of reperfusion. G1 administration at dose of 2.0 or $2.7 \mu \mathrm{mol} / \mathrm{kg}$ caused a pronounced bradycardia up to 200 and 100 beats/min, respectively and was accompanied by a sharp drop in SAP by 50 and $80 \%$, respectively, followed by gain of bradycardia.

We evaluated effects of G1 administration at doses of $0.4 ; 0.7$ and $1.3 \mu \mathrm{mol} / \mathrm{kg}$ on myocardial infarct size and cell membrane damage. The percentage ratios of area at risk to LV weight (AAR/LV, \%) were similar among G1-0.4, G1-0.7 and G1-1.3 groups and did not differ significantly from the values in control and the vehicle group (Figure 6A). Treatment with G1 at a dose of $0.4 \mu \mathrm{mol} / \mathrm{kg}$ or the vehicle alone did not affect the percentage ratio of myocardial infarction/area at risk (MI/AAR, \%) compare with control and the vehicle group. Administration of G1 at a dose of 0.7 or $1.3 \mu \mathrm{mol} /$ $\mathrm{kg}$ significantly reduced the percentage ratio of MI/AAR (on average by $25 \%$ compared with the value in control) thus indicating limitation of infarct size (Figure 6B). In addition, we analyzed the effects of G1 on plasma level of myocardial damage markers. In the steady state, plasma CK-MB and LDH activity of $270.1 \pm 24.2$ and $90.3 \pm 15.5$ IU/1 were respectively observed (Figure 7A-7B). The activity of CK-MB and LDH in blood plasma increased by 8 and 16 times, respectively, by the end of reperfusion in the control animals. Administration of G1 at dose of 0.4 $\mu \mathrm{mol} / \mathrm{kg}$ did not significantly affect the activity of both enzymes compared with control. Treatment with G1 at the dose of 0.7 or $1.3 \mu \mathrm{mol} / \mathrm{kg}$ reduced the CK-MB and LDH activity compared with the control group suggesting less damage to cell membranes.

\section{DISCUSSION}

Galaninergic system has been implicated in diverse higher order physiological functions including cognition, feeding, nociception, mood regulation, and neuroendocrine modulation [18]. The peripheral functional properties of galanin and its receptors have not yet been fully elucidated. One major limitation to delineate the pathophysiological role of galaninergic system is the lack of receptor subtype specific ligands. Numerous studies within the galaninergic system have mainly been focusing on the GalR1 subtype, which therefore is the best-characterized among the three receptors. However, an intense interest has lately been addressed towards the other two receptors, GalR2 and GalR3. The increased attention for GalR2 coincides with the introduction of the GalR2 selective ligand G1, which has lower affinity for GalR3 but does not affect GalR1 $[19,20]$. In the present study, we provide the first direct evidence that G1 has potent in vitro and in vivo cardioprotective activities against I/R-induced myocardial injury. Our data revealed that G1 prevents apoptotic cell death and mitochondrial ROS production under hypoxic stress in cardiomyoblasts. Furthermore, exogenous G1 attenuated cardiac damage, reduced infarct size and improved cardiac function in rat myocardial I/R injury suggesting the potential therapeutic value of G1 in heart diseases.

Compelling evidence has implicated a role for galanin and G1 in neuroprotection. For example, galanin knockout mice show a higher loss of pyramidal neurons in the hippocampus than wild-type mice after peripheral injection of kainic acid, and galanin or galanin (2-11) counteracts cell death induced by glutamate in hippocampal cultures [21, 22]. Our work demonstrates that exogenous G1 improves metabolic recovery of isolated rat heart subjected to I/R injury and cardiomyoblast survival after hypoxia and reoxygenation suggesting that galaninergic system may play an important role in metabolic remodeling of the heart in response to stress. Clinical studies and animal models demonstrate that abnormalities in cardiac energy metabolism are characteristic features of various heart diseases [23, 24]. The present results showing that the pre- or postischemic administrations of G1 improve recovery of myocardial energy status in response to $I / R$ damage suggest that peptide G1 is an important regulator of cardiac metabolism in the failing myocardium. The ability of G1 to preserve energy state of postischemic myocardium may be related to enhanced uptake and utilization of glucose. At the metabolic level, administration of galanin antagonist M35 to diabetic rats reduces insulin sensitivity, decreases GLUT4 content [25], and reduces GLUT4 mRNA expression in the membrane of myocytes and adipocytes [26, 27]. Alterations in glucose utilization in the heart may be a metabolic indicator of progressing chronic heart failure. Indeed, in patients with diabetes and 
coronary artery disease, the loss of GLUT4 content in the heart takes place simultaneously with the development of severe heart failure and ischemic cardiomyopathy [28, 29]. Importantly, we show that improvement of myocardial energy metabolism by peptide G1 was associated with the preservation of contractile function in isolated rat heart after I/R injury. In addition, the exogenous administration of peptide G1 at the onset of reperfusion reduced infarct size and plasma levels of necrosis markers in rats subjected to I/R suggesting a beneficial role for peptide G1 in limiting myocardial ischemic injury. This is the first demonstration of a cardioprotective activity of peptide G1. Compared to the more selective synthetic GalR2 agonists M1153 and M1145 [12, 30], the main advantages of G1 are better solubility, the simplicity of chemical structure and the fact that this peptide is a fragment of natural galanin.

Recent findings indicate that changes in mitochondrial ROS production could be relevant in cardiovascular pathophysiology, as such alterations may have an impact on cellular fate decisions [24]. Excessive ROS generation in mitochondria may provoke a state of oxidative stress, associated with pathophysiological progression in heart ischemic diseases. The intracellular changes during ischemia, including accumulation of $\mathrm{H}^{+}$and $\mathrm{Ca}^{2+}$ as well as the disruption of mitochondrial membrane potential, lead to the formation of ROS [31]. Furthermore, ROS accumulation directly activates the pathways of stress response, subsequently resulting in activation of apoptosis [32]. The primary ROS generated by mitochondria, as a result of mono-electronic reduction of $\mathrm{O}_{2}$, is superoxide anion $\mathrm{O}_{2}^{-}$, the precursor of most ROS and a mediator in oxidative chain reactions [33]. In the present study, our results revealed that G1 prevents mitochondrial $\mathrm{O}_{2}^{-}$formation in living cardiomyoblasts and apoptosis in response to hypoxic stress. These findings suggest that G1 may control oxidative stress status and activation of apoptotic cell death pathways in cardiac cells. One of the principal results of our study is that G1-dependent increased cardiomyoblast survival in response to hypoxic stress was associated with reduced generation of mitochondrial $\mathrm{O}_{2}^{-}$, a mediator in oxidative chain reactions. This association may be related to an increase in enzymatic antioxidant capacity induced by the peptide or to their direct antioxidant actions. Indeed, we have previously demonstrated that some endogenous peptides such as apelin, may exhibit powerful antioxidant properties [34, 35]. Further studies are required to define the potential mechanisms of how G1 inhibits mitochondrial ROS production and cell apoptosis and to identify the precise role of GalR2/GalR3 interactions in these processes.

In conclusion, our data provide the first evidence that the peptide $\mathrm{G} 1$ reduces $\mathrm{I} / \mathrm{R}$-associated cardiac dysfunction and myocardial damage. These beneficial effects are accompanied by substantial improvement of myocardial energy state and cell membrane integrity. In addition, we report that in cardiomyoblasts, G1 regulates mitochondrial ROS production and apoptosis in response to hypoxic stress. Taken together, these data collectively indicate that peptide G1 may be a promising new agent for cardioprotection against I/R injury.

\section{MATERIALS AND METHODS}

\section{Galanin peptides}

The peptide utilized in this study was rat galanin fragment G1 (Supplementary Table 1). Peptide G1 was synthesized by solid-phase method on Rink-amideresin (Nova BioChem, Switzerland). The synthesis was carried out in automatic mode with Fmoc-(9fluorenylmethoxycarbonyl)-technology on a peptide synthesizer Tribute-UV (Protein Technologies, Inc., USA). Fmoc amino acids (Nova BioChem, Switzerland) were coupled as 1-hydroxybenzotriazole esters. The peptide was cleaved from the resin using a solution of 95\% trifluoroacetic acid, 2.5\% triisopropylsilane and $2.5 \% \mathrm{H}_{2} \mathrm{O}$ for $2 \mathrm{~h}$. The crude product of solid-phase synthesis was purified by preparative reverse-phase HPLC with $98 \%$ homogeneity. The synthesized G1 has correct mass-spectrometric $\left(\mathrm{m} / \mathrm{z}=1137.3[\mathrm{M}+\mathrm{H}]^{+}\right)$and ${ }^{1} \mathrm{H}-\mathrm{NMR}$ characteristics.

Analytical HPLC was performed on a Gilson (France) system using 4.6×250 mm Kromasil-100 $5 \mu \mathrm{m}$ C18 columns (Sweden). Preparative HPLC was performed on a Knauer (Germany) system using Eurosphere octadecylsilyl columns $(20 \times 250 \mathrm{~mm}, 10 \mu \mathrm{m})$ (Knauer, Germany). Acetonitrile (Panreac, Spain) was used for HPLC. The mass spectra were recorded on a VISION 2000 mass spectrometer (Termobioanalysis corp., Finnigan, United States) with matrix assisted laser desorbtion ionization time-of-flight (MALDI-TOF) method. ${ }^{1} \mathrm{H}-\mathrm{NMR}$ was performed on WH-500 Bruker $500 \mathrm{MHz}$ (Germany) in DMSO-d6 at $300 \mathrm{~K}$, peptide concentration was 2-3 mg/ $\mathrm{ml}$, chemical shifts in ${ }^{1} \mathrm{H}-\mathrm{NMR}$ spectra were measured relative to an internal standard tetramethylsilane.

\section{Reagents}

Enzymes and chemicals for in vivo experiments were purchased from Sigma Chemical Co. (St Louis, MO USA). Solutions were prepared using deionized water (Millipore Corp. Bedford, MA, USA).

\section{Animals}

Male Wistar rats weighing 300 to $340 \mathrm{~g}$ were housed in cages in groups of three, maintained at $20-30^{\circ} \mathrm{C}$ with a natural light-dark cycle. All animals had free access to standard pelleted diet (Aller Petfood, St. Petersburg, 
Russia) and tap water. The care and use of the animals were conducted in accordance with the European Convention for the Protection of Vertebrate Animals Used for Experimental and other Scientific Purposes (No 123 of 18 March 1986).

\section{Isolated perfused rat hearts}

The isolated heart provides a highly reproducible preparation that can be studied in a time-dependent manner. It allows a broad spectrum of biochemical, physiological, morphological and pharmacological indices to be measured, permitting detailed analysis of ventricular mechanics, metabolism and coronary vascular responses. In principle, two different isolated heart models exist: 1) the isolated heart according to Langendorff (1895), in which hearts are supplied with coronary flow through retrograde perfusion and 2) the working, fluid-ejecting heart, in which hearts are perfused via the left atrium and eject fluid through the left ventricle into the aorta thus perfusing their own coronaries. The present study is designed with a combination of features from both the Langendorff (nonworking) and the Neely (working) systems. The working heart performs pressure-volume work, an important distinction from its Langendorff counterpart, which performs energetically less demanding isovolumetric contractions.

Briefly, rats were heparinized (1600 IU/kg body weight, intraperitoneally (i.p.)) and anaesthetized with urethane (1.3 g/kg body weight, i.p.). Hearts were perfused with $\mathrm{KHB}$ containing (in $\mathrm{mM}$ ): $\mathrm{NaCl} 118, \mathrm{KCl}$ 4.7, $\mathrm{CaCl}_{2} 3.0, \mathrm{Na}_{2}$ EDTA 0.5, $\mathrm{KH}_{2} \mathrm{PO}_{4} 1.2, \mathrm{MgSO}_{4} 1.2$, $\mathrm{NaHCO}_{3} 25.0$ and glucose 11.0. It was oxygenated with a mixture of $95 \% \mathrm{O}_{2}$ and $5 \% \mathrm{CO}_{2} ; \mathrm{pH}$ was $7.4 \pm 0.1$ at $37^{\circ} \mathrm{C}$. KHB was passed through a $5 \mu \mathrm{m}$ Millipore filter (Bedford, MA, USA) before use. A needle was inserted into the LV cavity to register LV pressure via a Gould Statham P50 transducer, SP 1405 monitor and a Gould Brush SP 2010 recorder (Gould, Oxnard, Ca, USA). The contractile function intensity index was calculated as the LVDP $\times H R$, where LVDP is the difference between LV systolic and LV end-diastolic pressure. Cardiac pump function was assessed by $\mathrm{CO}$, the sum of aortic output and coronary flow as previously described [34].

The steady state values of cardiac function were recorded after preliminary 20 -min perfusion in working mode according to a modified method of Neely under constant left atrium pressure and aortic pressure of 20 and $100 \mathrm{~cm} \mathrm{H}_{2} \mathrm{O}$, respectively. After the steady state period, the control hearts were perfused in Langendorff mode for $5 \mathrm{~min}$ at a constant flow rate of $4 \mathrm{ml} / \mathrm{min}$, and then they were subjected to 35-min normothermic global ischemia followed by 5 -min Langendorff perfusion with subsequent 30-min working reperfusion by Neely method (Figure 4A).
In order to provide a successful G1 transport to cardiomyocyte membranes of ischemic heart we had to profoundly increase G1 concentration in KHB compared to cell experiments. Thus, in the G1-I group, 5-min Langendorff perfusion with KHB containing 40, 80, 160, 240 or $280 \mu \mathrm{M}$ G1 was applied before global ischemia. Further procedure was the same as for the control group. The hearts of the G1-R group were perfused for $5 \mathrm{~min}$ with KHB containing 40, 80, 160, 240 or $280 \mu \mathrm{M}$ G1 in Langendorff mode after global ischemia. Other experimental stages were the same as in control. The final concentration of dimethyl sulfoxide (DMSO) in KHB with peptide G1 was $0.2 \%$. In a separate series of experiments, it was found that 5 -min infusion of KHB containing $0.2 \%$ DMSO did not affect the recovery of cardiac function after ischemia.

\section{Analysis of metabolites}

After preliminary working perfusion (steady state) and at the end of reperfusion, the hearts were freezeclamped in liquid nitrogen for metabolite analysis. Frozen isolated perfused hearts were quickly homogenized in cooled $6 \% \mathrm{HClO}_{4}(10 \mathrm{ml} / \mathrm{g})$ using an Ultra-Turrax T-25 homogenizer (IKA-Labortechnik, Staufen, Germany), and the homogenates were centrifuged at $2800 \times \mathrm{g}$ for $10 \mathrm{~min}$ at $4{ }^{\circ} \mathrm{C}$. The supernatants were then neutralized with $5 \mathrm{M}$ $\mathrm{K}_{2} \mathrm{CO}_{3}$ to $\mathrm{pH} 7.40$, and the extracts were centrifuged after cooling to remove $\mathrm{KClO}_{4}$ precipitate. Tissue dry weights were determined by weighing a portion of the pellets after extraction with $6 \% \mathrm{HClO}_{4}$ and drying overnight at $110^{\circ} \mathrm{C}$. Concentrations of ATP, ADP, AMP, PCr, creatine $(\mathrm{Cr})$ and lactate in neutralized tissue extracts were determined by enzymatic methods [36].

\section{In vivo rat model of $\mathrm{I} / \mathrm{R}$ injury}

Rats were anesthetized with 20\% urethane (120 mg/ $\mathrm{kg}$, i.p.) and artificially ventilated with a KTR-5 animal respirator (Hugo Sacks Electronik) with a volume of 2-3 $\mathrm{ml}$ at a rate of $70-75$ breaths/min. Further preparation of animals was performed as described earlier [37]. Arterial blood pressure was recorded with a pressure transducer (Statham p23Db, Oxnard, USA) using a polygraph Biograph-4 (St. Petersburg, Russia). The mean arterial pressure, heart rate and standard lead II ECG were recorded on a computer using a LabVIEW 7.1 data acquisition system (National Instruments, USA).

After 30-min stabilization of hemodynamic parameters (steady state), LAD coronary artery was occluded for $40 \mathrm{~min}$ to simulate regional ischemia; the duration of subsequent reperfusion was $1 \mathrm{~h}$. In the experimental series, G1 was administrated by i.v. bolus injection at the onset of reperfusion at doses of $0.4 ; 0.7$; $1.3 ; 2.0$ or $2.7 \mu \mathrm{mol} / \mathrm{kg}$ (groups G1-0.4; G1-0.7; G11.3 ; G1-2.0 or G1-2.7, respectively). An equal volume 
of saline $(0.5 \mathrm{ml})$ was injected in the control series of experiments. The influence of a vehicle, $0.5 \% \mathrm{DMSO}$, on myocardial infarct size was studied in a separate series of experiments. Additionally, effects of i.v. G1 administration on hemodynamic data were evaluated. At the end of experiments, LAD coronary artery was occluded and $2 \mathrm{ml}$ of $2 \%$ Evans Blue (Sigma, USA) solution was injected through the jugular vein to distinguish the myocardial nonischemic area from the AAR.

\section{Determination of myocardial infarct size}

After staining with Evans Blue, the heart was excised and the LV was frozen. A frozen LV was transversely cut into $1.5 \mathrm{~mm}$ thick slices which were incubated in $0.1 \mathrm{M}$ sodium phosphate buffer $\mathrm{pH}$ 7.4, containing 1\% 2,3,5-triphenyl-tetrazolium chloride (TTC, Sigma, USA) $10 \mathrm{~min}$ at $37^{\circ} \mathrm{C}$. The slices were fixed in $10 \%$ formalin for $5 \mathrm{~min}$. Then they were placed between two transparent glasses and captured using a scanner at 600 d.p.i. resolution; the saved images were analyzed by computerized planimetry using Imagecal software. The slices were then weighed for determination of LV weight. The AAR was expressed as a percentage of LV weight; MI was expressed as a percentage of the AAR in each group.

\section{Determination of necrosis markers}

At the end of the steady state and reperfusion, blood samples were collected for plasma separation. Plasma LDH activity was determined enzymatically with pyruvate as substrate by using standard kits from BioSystems S.A. (Barcelona, Spain). Plasma CK-MB activity was assessed by an immunoinhibition method using standard kits from BioSystems S.A. (Barcelona, Spain) from the rate of nicotinamide adenine dinucleotide phosphate formation by means of the hexokinase and glucose-6-phosphate dehydrogenase coupled reactions.

\section{Cell culture and treatments}

Rat ventricular myocardial $\mathrm{H} 9 \mathrm{C} 2$ cells were obtained from American Type Culture Collection (Manassas, VA, USA). H9C2 cells at passages 18 to 24 were seeded in 24 or 96-well cell culture plates with Dulbecco's Modified Eagle Medium (Invitrogen, CergyPontoise, France) containing 10\% Fetal Bovine Serum (Invitrogen, Cergy Pontoise, France), $100 \mathrm{U} \mathrm{mL}^{-1}$ penicillin and $100 \mu \mathrm{g} \mathrm{mL} \mathrm{m}^{-1}$ streptomycin at $37^{\circ} \mathrm{C}$ in a humidified atmosphere of $5 \% \mathrm{CO}_{2}$ and were used at less than $80 \%$ of confluence.

\section{Measurement of mitochondrial $\mathrm{O}_{2}^{-}$production}

The mitochondrial levels of ROS were determined in $\mathrm{H} 9 \mathrm{C} 2$ cells subjected to hypoxia $\left(1 \% \mathrm{O}_{2}, 5 \% \mathrm{CO}_{2}\right)$ for $16 \mathrm{~h}$ followed by $4 \mathrm{~h}$ of reoxygenation $\left(95 \% \mathrm{O}_{2}, 5 \% \mathrm{CO}_{2}\right)$ using mitochondrial superoxide indicator $\left(\mathrm{MitoSOX}^{\mathrm{TM}}\right.$ red, Life Technologies). Before hypoxia the H9C2 were pretreated with G1 analogue for $20 \mathrm{~min}$. After reoxygenation, cells were washed once with phosphate-buffered saline (PBS) and incubated in $1 \mu \mathrm{M}$ MitoSOX red for $30 \mathrm{~min}$ at $37^{\circ} \mathrm{C}$ followed by three washes with PBS. The fluorescence was then measured at the excitation wavelength of $510 \mathrm{nM}$ and emission wavelength of $580 \mathrm{nM}$.

\section{Evaluation of apoptosis}

The apoptosis level was assessed using the TUNEL system according to manufacturer's instructions (Promega, Madison, WI, USA) as described previously [38]. TUNEL is a general method to detect nuclear DNA fragmentation during apoptosis. TUNEL technique relies on the use of endogenous enzymes that allow the incorporation of labeled nucleotides into the $3^{\prime}$-hydroxyl $\left(3^{\prime} \mathrm{OH}\right)$ recessed termini of DNA breaks. The added value in this approach resides in the possibility of evaluating both morphological and staining features in the same sample.

\section{ATP measurement}

ATP was measured with the CellTiter-Glo ${ }^{\circledR}$ Luminescent Cell Viability Assay from Promega (Madison, WI). H9C2 cells were seeded at a density of 2 x $10^{5}$ cells/ml with $100 \mu \mathrm{l}$ per well in a white 96 -well plate and allowed to grow for $24 \mathrm{~h}$. Before addition of $400 \mu \mathrm{M}$ of $\mathrm{H}_{2} \mathrm{O}_{2}$ for $4 \mathrm{~h}, \mathrm{H} 9 \mathrm{C} 2$ cells were pretreated for $20 \mathrm{~min}$ with $\mathrm{G} 1$ at the different doses $(10,50$ and $250 \mathrm{nM})$. The cells were equilibrated at room temperature for $30 \mathrm{~min}$ and, followed by addition of the CellTiter-Glo ${ }^{\circledR}$ reagents, per manufactured instructions. The luminescence was read after a 10 min incubation of the reagents on the INFINITE F500 on luminescence module (TECAN, Switzerland, Mennedorf) and expressed as mean percentage of control group.

\section{Statistical analysis}

Data are presented as means \pm SEM. Results were analyzed by one-way ANOVA followed by Bonferroni multiple range test post-hoc analysis for calculation differences between more than two groups. Comparisons between two groups involved use of the Student's unpaired t-test. All statistical analyses were performed using SigmaPlot version 12 (Systat Software Inc, San Jose, CA). A $p<0.05$ was defined as significant.

\section{ACKNOWLEDGMENTS}

This work was supported by grants from the National Institute of Health and Medical Research (INSERM), Région Midi-Pyrénées, ERASMUS 
MUNDUS MEDEA project and The Russian Foundation for Basic Research (grant No. 14-04-00012a).

\section{CONFLICTS OF INTEREST}

The authors declare no conflicts of interest.

\section{Author contributions}

A.T., O.P. and O.K. conceived and designed the study. O.P., I.S., L.S., V.S. and O.V. performed in vivo experiments. A.T. and O.K. performed in vitro experiments. V.S. and L.S. performed microsurgery procedures on rats. M.S., M.P. and A.M. synthesized and purified the galanin analogue. F.B., A.T., O.P. and O.K. analyzed the data and wrote the paper. H.T., F.B. and M.C. contributed to tools and discussion.

\section{REFERENCES}

1. Fang PH, Yu M, Ma YP, Li J, Sui YM, Shi MY. Central nervous system regulation of food intake and energy expenditure: role of galanin-mediated feeding behavior. Neurosci Bull. 2011; 27: 407-12. doi: 10.1007/ s12264-011-1841-7.

2. Diaz-Cabiale Z, Parrado C, Narvaez M, Millon C, Puigcerver A, Fuxe K, Narvaez JA. Neurochemical modulation of central cardiovascular control: the integrative role of galanin. EXS. 2010; 102: 113-31.

3. Abbott SB, Pilowsky PM. Galanin microinjection into rostral ventrolateral medulla of the rat is hypotensive and attenuates sympathetic chemoreflex. Am J Physiol Regul Integr Comp Physiol. 2009; 296: R1019-26. doi: 10.1152/ ajpregu.90885.2008.

4. Chen A, Li M, Song L, Zhang Y, Luo Z, Zhang W, Chen $\mathrm{Y}, \mathrm{He}$ B. Effects of the Galanin Receptor Antagonist M40 on Cardiac Function and Remodeling in Rats with Heart Failure. Cardiovasc Ther. 2015; 33: 288-93. doi: 10.1111/1755-5922.12144.

5. He B, Shi M, Zhang L, Li G, Zhang L, Shao H, Li J, Fang P, Ma Y, Shi Q, Sui Y. Beneficial effect of galanin on insulin sensitivity in muscle of type 2 diabetic rats. Physiol Behav. 2011; 103: 284-9. doi: 10.1016/j. physbeh.2011.02.023.

6. Elliott-Hunt CR, Holmes FE, Hartley DM, Perez S, Mufson EJ, Wynick D. Endogenous galanin protects mouse hippocampal neurons against amyloid toxicity in vitro via activation of galanin receptor-2. J Alzheimers Dis. 2011; 25: 455-62. doi: 10.3233/JAD-2011-110011.

7. Habecker BA, Gritman KR, Willison BD, Van Winkle DM. Myocardial infarction stimulates galanin expression in cardiac sympathetic neurons. Neuropeptides. 2005; 39: 89-95. doi: 10.1016/j.npep.2004.11.003.

8. Kocic I. The influence of the neuropeptide galanin on the contractility and the effective refractory period of guinea-pig heart papillary muscle under normoxic and hypoxic conditions. J Pharm Pharmacol. 1998; 50: 1361-4.

9. Lautatzis ME, Vrontakis M. (2011). Profile of Galanin in Embryonic Stem Cells and Tissues, Embryonic Stem Cells Basic Biology to Bioengineering, Prof. Michael Kallos (Ed.), ISBN: 978-953-307-278-4, InTech.

10. Floren A, Land T, Langel U. Galanin receptor subtypes and ligand binding. Neuropeptides. 2000; 34: 331-7. doi: 10.1054/npep.2000.0808.

11. Lang R, Gundlach AL, Kofler B. The galanin peptide family: receptor pharmacology, pleiotropic biological actions, and implications in health and disease. Pharmacol Ther. 2007; 115: 177-207. doi: 10.1016/j.pharmthera.2007.05.009.

12. Langel U. Galanin receptor ligands. Springerplus. 2015; 4 : L18. doi: 10.1186/2193-1801-4-S1-L18.

13. Pang L, Hashemi T, Lee HJ, Maguire M, Graziano MP, Bayne M, Hawes B, Wong G, Wang S. The mouse GalR2 galanin receptor: genomic organization, cDNA cloning, and functional characterization. J Neurochem. 1998; 71: 2252-9.

14. Brown EM, MacLeod RJ. Extracellular calcium sensing and extracellular calcium signaling. Physiol Rev. 2001; 81: 239-97.

15. Webling K, Runesson J, Lang A, Saar I, Kofler B, Langel U. Ala5-galanin (2-11) is a GAL2R specific galanin analogue. Neuropeptides. 2016. doi: 10.1016/j.npep.2016.08.008.

16. Mazarati A, Lundstrom L, Sollenberg U, Shin D, Langel U, Sankar R. Regulation of kindling epileptogenesis by hippocampal galanin type 1 and type 2 receptors: The effects of subtype-selective agonists and the role of G-protein-mediated signaling. J Pharmacol Exp Ther. 2006; 318: 700-8. doi: 10.1124/jpet.106.104703.

17. Zhou T, Chuang CC, Zuo L. Molecular Characterization of Reactive Oxygen Species in Myocardial IschemiaReperfusion Injury. Biomed Res Int. 2015; 2015: 864946. doi: 10.1155/2015/864946.

18. Gundlach AL, Burazin TC, Larm JA. Distribution, regulation and role of hypothalamic galanin systems: renewed interest in a pleiotropic peptide family. Clin Exp Pharmacol Physiol. 2001; 28: 100-5.

19. Liu HX, Brumovsky P, Schmidt R, Brown W, Payza K, Hodzic L, Pou C, Godbout C, Hokfelt T. Receptor subtypespecific pronociceptive and analgesic actions of galanin in the spinal cord: selective actions via GalR1 and GalR2 receptors. Proc Natl Acad Sci U S A. 2001; 98: 9960-4. doi: 10.1073/pnas.161293598.

20. Lu X, Lundstrom L, Bartfai T. Galanin (2-11) binds to GalR3 in transfected cell lines: limitations for pharmacological definition of receptor subtypes. Neuropeptides. 2005; 39: 165-7. doi: 10.1016/j.npep.2004.12.013.

21. Elliott-Hunt CR, Marsh B, Bacon A, Pope R, Vanderplank P, Wynick D. Galanin acts as a neuroprotective factor to the hippocampus. Proc Natl Acad Sci U S A. 2004; 101: 510510. doi: 10.1073/pnas.0304823101. 
22. Pirondi S, Fernandez $\mathrm{M}$, Schmidt $\mathrm{R}$, Hokfelt T, Giardino L, Calza L. The galanin-R2 agonist AR-M1896 reduces glutamate toxicity in primary neural hippocampal cells. J Neurochem. 2005; 95: 821-33. doi: 10.1111/j.1471-4159.2005.03437.x.

23. Neubauer $\mathrm{S}$. The failing heart--an engine out of fuel. N Engl J Med. 2007; 356: 1140-51. doi: 10.1056/NEJMra063052.

24. Parra V, Verdejo H, del Campo A, Pennanen C, Kuzmicic J, Iglewski M, Hill JA, Rothermel BA, Lavandero S. The complex interplay between mitochondrial dynamics and cardiac metabolism. J Bioenerg Biomembr. 2011; 43: 47-51. doi: 10.1007/s10863-011-9332-0.

25. Fang P, Sun J, Wang X, Zhang Z, Bo P, Shi M. Galanin participates in the functional regulation of the diabetic heart. Life Sci. 2013; 92: 628-32. doi: 10.1016/j.1fs.2013.01.024.

26. Leto D, Saltiel AR. Regulation of glucose transport by insulin: traffic control of GLUT4. Nat Rev Mol Cell Biol. 2012; 13: 383-96. doi: 10.1038/nrm3351.

27. Guo L, Shi M, Zhang L, Li G, Zhang L, Shao H, Fang P, Ma Y, Li J, Shi Q, Sui Y. Galanin antagonist increases insulin resistance by reducing glucose transporter 4 effect in adipocytes of rats. Gen Comp Endocrinol. 2011; 173: 15963. doi: 10.1016/j.ygcen.2011.05.011.

28. Adachi H, Ohno T, Oguri M, Oshima S, Taniguchi K. Effect of insulin sensitivity on severity of heart failure. Diabetes Res Clin Pract. 2007; 77 Suppl 1: S258-62. doi: 10.1016/j. diabres.2007.01.068.

29. Doehner W, Gathercole D, Cicoira M, Krack A, Coats AJ, Camici PG, Anker SD. Reduced glucose transporter GLUT4 in skeletal muscle predicts insulin resistance in non-diabetic chronic heart failure patients independently of body composition. Int J Cardiol. 2010; 138: 19-24. doi: 10.1016/j.ijcard.2008.07.004.

30. Saar I, Runesson J, McNamara I, Jarv J, Robinson JK, Langel U. Novel galanin receptor subtype specific ligands in feeding regulation. Neurochem Int. 2011; 58: 714-20. doi: 10.1016/j.neuint.2011.02.012.

31. Feissner RF, Skalska J, Gaum WE, Sheu SS. Crosstalk signaling between mitochondrial $\mathrm{Ca} 2+$ and ROS. Front Biosci (Landmark Ed). 2009; 14: 1197-218.

32. Simon HU, Haj-Yehia A, Levi-Schaffer F. Role of reactive oxygen species (ROS) in apoptosis induction. Apoptosis. 2000; 5: 415-8.

33. Turrens JF. Mitochondrial formation of reactive oxygen species. J Physiol. 2003; 552: 335-44. doi: 10.1113/ jphysiol.2003.049478.

34. Pisarenko OI, Lankin VZ, Konovalova GG, Serebryakova LI, Shulzhenko VS, Timoshin AA, Tskitishvili OV, Pelogeykina YA, Studneva IM. Apelin-12 and its structural analog enhance antioxidant defense in experimental myocardial ischemia and reperfusion. Mol Cell Biochem. 2014; 391: 241-50. doi: 10.1007/s11010-014-2008-4.

35. Foussal C, Lairez O, Calise D, Pathak A, GuilbeauFrugier C, Valet P, Parini A, Kunduzova O. Activation of catalase by apelin prevents oxidative stress-linked cardiac hypertrophy. FEBS Lett. 2010; 584: 2363-70. doi: 10.1016/j.febslet.2010.04.025.

36. Bergmeyer HU. Methods of enzymatic analysis. Academic Press. 1974: 1464-7; 772-776; 777-781; 2127-31.

37. Pisarenko OI, Shulzhenko VS, Studneva IM, Serebryakova LI, Pelogeykina YA, Veselova OM. Signaling pathways of a structural analogue of apelin-12 involved in myocardial protection against ischemia/reperfusion injury. Peptides. 2015; 73: 67-76. doi: 10.1016/j.peptides.2015.09.001.

38. Pchejetski D, Foussal C, Alfarano C, Lairez O, Calise D, Guilbeau-Frugier C, Schaak S, Seguelas MH, Wanecq E, Valet P, Parini A, Kunduzova O. Apelin prevents cardiac fibroblast activation and collagen production through inhibition of sphingosine kinase 1. Eur Heart J. 2012; 33: 2360-9. doi: 10.1093/eurheartj/ehr389. 